\title{
On Theory of Superheterodyne FELs with Longitudinal Electrostatic Undulator
}

\author{
A.V. Lysenko ${ }^{1, *}$, A.Yu. Brusnik ${ }^{1}$, I.I. Volk ${ }^{1, \dagger}$, M.A. Korovai ${ }^{1}$, S.S. Ilin ${ }^{1}$, O.L. Bunetskyi ${ }^{2}$ \\ ${ }^{1}$ Sumy State University, 2, Rimsky-Korsakov Str., 40007 Sumy, Ukraine \\ ${ }^{2}$ O.Ya. Usikov Institute for Radiophysics and Electronics of the National Academy of Sciences of Ukraine, \\ 12, Ac. Proskura Str., 61085 Kharkiv, Ukraine
}

(Received 29 March 2020; revised manuscript received 20 August 2020; published online 25 August 2020)

\begin{abstract}
Within the framework of the quadratic nonlinear approximation, the amplification characteristics of a single-stream superheterodyne free electron laser were analysed. Such device used two mechanisms of the electromagnetic signal amplification: the mechanism of parametric amplification of the electromagnetic wave using a traditional undulator with transverse periodically reversing magnetic field, and an additional amplification mechanism using longitudinal electrostatic undulator. By means of the averaged characteristics method, we obtained a system of differential equations describing the dynamics of the wave harmonics in superheterodyne free electron laser. Plural three-wave parametric resonant interactions between harmonics of different space charge wave types were discovered in the system. To implement such plural interactions, it was sufficient to have a monochromatic electrostatic pump field. We achieved and analysed an expression for the growth rate related to both the parametric instability of transverse waves and the parametric instability of longitudinal waves in an electrostatic undulator. We showed that the additional gain provided by the electrostatic undulator found its most efficient use in the systems characterized by relatively small values of the beam relativistic factor and rather high values of the electromagnetic signal frequency. We demonstrated the prospect of using such superheterodyne free electron lasers with longitudinal electrostatic undulator as a powerful amplifier in the millimeter-submillimeter wavelength range.
\end{abstract}

Keywords: Superheterodyne Free-electron laser, Electrostatic undulator, Parametric resonance, Space charge waves, Wave growth rates.

DOI: 10.21272/jnep.12(4).04037

PACS numbers: 41.60.Cr, 52.59.Ye

\section{INTRODUCTION}

The creation of new sources of high-power terahertz radiation is one of the main trends in the development of modern relativistic plasma electronics [1-3]. Despite the fact that terahertz radiation has a wide range of applications, few devices are capable of producing powerful radiation in the millimeter-infrared range [3]. Therefore, theoretical studies of new powerful radiation sources of this wavelength range are important and relevant.

One of the new sources of powerful terahertz radiation is superheterodyne free-electron laser (FEL) with longitudinal wave amplifier [4], which uses a longitudinal electrostatic undulator for further amplification of the electromagnetic signal wave. Note that the use of electrostatic undulators in FEL technology has been known for a long time [5-8]. However, the simultaneous use of two electromagnetic signal amplification mechanisms has been proposed in [4] for the first time. To date, a detailed study of the proposed FEL has not been carried out. In [9] the amplification of the space charge waves (SCWs) in the section of the longitudinal waves amplification in the klystron model of such device has only been studied.

We partially eliminate this deficiency in the presented work. Here, within the framework of a quadratic nonlinear approximation, we perform an analysis of the electromagnetic signal amplification in one-section model of superheterodyne FEL. The device under study uses two mechanisms of electromagnetic signal amplification: the mechanism of parametric amplification of the electromagnetic wave using a traditional undulator with transverse periodically reversing magnetic field, and an additional amplification mechanism using longitudinal electrostatic undulator. We obtain the equations describing the nonlinear wave dynamics in the studied system, and determine wave growth rates. We find the range of parameters at which this device effectively amplifies electromagnetic radiation.

\section{PARAMETRIC RESONANCES, FEL MODEL}

We study the physical processes in one-section model of a superheterodyne FEL with longitudinal electrostatic undulator (Fig. 1). A relativistic electron beam (Fig. 1, unit 1) moves along the axis of the device. We consider that a fixed ion background compensates the space charge of the relativistic electron beam (REB). We assume that the model is homogeneous in the transverse plane. The relativistic beam (Fig. 1, unit 1) passes through a magnetic field created by a multi-harmonic $\mathrm{H}$ ubitron undulator (Fig. 1, unit 2) with main harmonic undulation period $\Lambda_{\mathrm{I}}$ (wave number $k_{2,1}=2 \pi / \Lambda_{\mathrm{I}}$ ). The magnetic field of the undulator in the device under study acts as the first pump. Longitudinal electrostatic field is also created in the working bulk of the device with the help of the modulator 3. This field is characterized by the main harmonic undulation period $\Lambda_{\mathrm{II}}$ (wave number $\left.k_{\gamma, 1}=2 \pi / \Lambda_{\mathrm{II}}\right)$. A transverse electromagnetic wave with the first harmonic frequency $\omega_{1}$ and a wave number $k_{1,1}$ is supplied to the input of the device. We assume that all

\footnotetext{
*lysenko_@ukr.net

†y.volk@mss.sumdu.edu.ua
} 
waves in the system under study are multiharmonic in general case.

As a result of the parametric resonant interaction of the transverse electromagnetic signal wave $\left\{\omega_{1}, k_{1}\right\}$ and the transverse H-ubitron magnetic pump field $\left\{k_{2}\right\}$, a longitudinal slow SCW with the first harmonic frequency $\omega_{\alpha}$ and the wave number $k_{\alpha, 1}$ is excited in relativistic electron beam. The frequencies and wave numbers of the first harmonics of these waves taking part in the parametric resonances are described by the relations

$$
\omega_{\alpha}=\omega_{1}, k_{\alpha, 1}=k_{1,1}+k_{2,1} .
$$

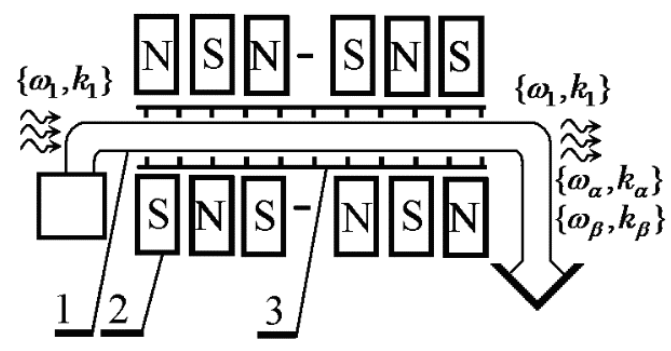

Fig. 1 - One section model scheme of the superheterodyne FEL with longitudinal electrostatic undulator: 1 - relativivstic electron beam; 2 - undulator that creates transverse H-ubitron magnetic field; 3 - undulator that creates longitudinal electrostatic field

Due to the appropriate choice of parameters, conditions for the implementation of another parametric resonant interaction are met in the investigated FEL. Namely, as a result of the interaction between the longitudinal electrostatic field of the second pump $\left\{k_{\gamma}\right\}$ and the slow SCW $\left\{\omega_{\alpha}, k_{\alpha}\right\}$, a fast SCW with the first harmonic frequency $\omega_{\beta}$ and the wave number $k_{\beta, 1}$ is excited. The frequencies and wave numbers of these longitudinal SCWs satisfy the conditions of the second parametric resonance

$$
\omega_{\alpha}=\omega_{\beta}, k_{\alpha, 1}=k_{\gamma, 1}+k_{\beta, 1} .
$$

As known [9, 10], the slow SCW is characterized by negative energy while the fast one by positive energy. Due to the fact that waves with different energy sign take part in the parametric resonance the amplitudes of both slow and fast SCWs increase. This growth is ensured by the transition of part of the kinetic energy of the REB longitudinal motion into the SCW energy. It provides additional amplification of the slow SCW, which in its turn is transmitted to the transverse electromagnetic signal through the parametric resonance mechanism (1).

\section{BASIC EQUATIONS}

The relativistic quasi-hydrodynamic equation, the continuity equation and the Maxwell's equations act as initial [10-12]. To solve the problem of motion and find the concentrations we use the method of averaged characteristics [10]. The method of slowly varying amplitudes is used to solve the problem of electromagnetic fields excitation. We consider that the electromagnetic signal wave, the longitudinal electron waves and the pump fields have the multiharmonic nature in general case:

$$
\begin{aligned}
& \mathbf{E}_{1}=\sum_{m=1}^{N}\left[E_{1, m} \exp \left(i p_{1, m}\right)+c . c .\right] \mathbf{e}_{x}, \\
& \mathbf{B}_{1}=\sum_{m=1}^{N}\left[B_{1, m} \exp \left(i p_{1, m}\right)+c . c .\right] \mathbf{e}_{y}, \\
& \mathbf{E}_{\alpha}=\sum_{m=1}^{N}\left[E_{\alpha, m} \exp \left(i p_{\alpha, m}\right)+c . c .\right] \mathbf{e}_{z}, \\
& \mathbf{E}_{\gamma}=\sum_{m=1}^{N}\left[E_{\gamma, m} \exp \left(i p_{\gamma, m}\right)+c . c .\right] \mathbf{e}_{z}, \\
& \mathbf{E}_{\beta}=\sum_{m=1}^{N}\left[E_{\beta, m} \exp \left(i p_{\beta, m}\right)+c . c .\right] \mathbf{e}_{z}, \\
& \mathbf{B}_{2}=\sum_{m=1}^{N}\left[B_{2, m} \exp \left(i p_{2, m}\right)+c . c .\right] \mathbf{e}_{y},
\end{aligned}
$$

where $N$ is the number of considered harmonics, $m$ is the harmonic number; $p_{1, m}=m \omega_{1}-k_{1, m} z$ is the electromagnetic signal wave phase, $p_{\alpha, m}=m \omega_{\alpha}-k_{\alpha, m} z$ is the slow SCW phase, $p_{\gamma, m}=-m k_{\gamma} z$ is the longitudinal electrostatic pump field phase, $p_{\beta, m}=m \omega_{\beta}-k_{\beta, m} z$ is the fast SCW phase, $p_{2, m}=-m k_{2} z$ is the H-ubitron pump field phase. Thus, the electric and magnetic fields in the working bulk of the system are as follows:

$$
\mathbf{E}=\mathbf{E}_{1}+\mathbf{E}_{\alpha}+\mathbf{E}_{\beta}+\mathbf{E}_{\gamma} ; \mathbf{B}=\mathbf{B}_{1}+\mathbf{B}_{2} .
$$

We use a hierarchical approach to the theory of oscillations and waves [10] to solve the problem of motion and the continuity equation. As a result, we obtain expressions for the fast-oscillating components in analytical form and differential equations for the slowly varying components which do not depend on the fastoscillating components. Details of such transformations are outlined in [11].

Next we substitute the solutions for velocity and concentration into the Maxwell's equations and apply the method of slowly varying amplitudes. We consider that a quasistationary mode of interaction is realized, when the amplitudes of the fields depend only on the coordinate and are independent on time. As a result of these transformations we get a system of differential equations for the amplitudes of interacting waves in the framework of nonlinear quadratic approximation

$$
\begin{gathered}
C_{1,1,1} \frac{d E_{1,1}}{d z}=C_{3,1,1}^{I} E_{\alpha, 1} B_{2,1}^{*} \\
C_{1, \alpha, m} \frac{d E_{\alpha, m}}{d z}=C_{3, \alpha, m}^{I} E_{1, m} B_{2, m} \cdot \delta_{m, 1}+C_{3, \alpha, m}^{I I} E_{\beta, m} E_{\gamma, m} \\
C_{1, \beta, m} \frac{d E_{\beta, m}}{d z}=C_{3, \beta, m}^{I I} E_{\alpha, m} E_{\gamma, m}^{*} .
\end{gathered}
$$

The frequencies and wave numbers of the interacting waves satisfy the dispersion equations:

$$
D_{1, m} \equiv\left[k_{1, m}^{2}-\frac{\omega_{1, m}^{2}}{c^{2}}-\frac{\omega_{p}^{2}}{\gamma_{0} c^{2}}\right]=0,
$$




$$
D_{\chi, m} \equiv-i k_{\chi, m}\left(1-\frac{\omega_{p}^{2}}{\Omega_{\chi, m}^{2} v_{z 0}^{2} \gamma_{0}^{3}}\right)=0 .
$$

In these equations $\cdot \delta_{m, 1}$ is the Kronecker delta, in$\operatorname{dex} \chi$ takes values $\alpha, \beta$;

$$
\begin{aligned}
& C_{1,1, m}=\frac{\partial D_{1, m}}{\partial\left(-i k_{1, m}\right)} \text {; } \\
& C_{3,1, m}^{I}=\frac{\omega_{p}^{2} m \cdot \omega_{1} \cdot e}{2 \Omega_{\alpha, m} m_{e} \gamma_{0}^{4} k_{1, m} k_{2, m} c^{3} v_{z 0}^{2}}\left(\frac{v_{z 0}^{2} \gamma_{0}^{2}}{c^{2}}-\frac{k_{\alpha, m}}{\Omega_{\alpha, m}}\right) \text {; } \\
& C_{1, \chi, m}=\frac{\partial D_{\chi, m}}{\partial\left(-i k_{\chi, m}\right)} \text {; } \\
& C_{3, \alpha, m}^{I}=\frac{\omega_{p}^{2} e k_{\alpha, m}}{v_{z 0}^{2} \Omega_{\alpha, m}^{2} m_{e} \gamma_{0}^{2} c^{2} k_{2, m}}\left(\frac{v_{z 0}}{c}-\frac{k_{\alpha, m} c}{m \cdot \omega_{\alpha}}\right) ; \\
& C_{3, \alpha, m}^{I I}=\frac{-k_{\alpha, m} \omega_{p}^{2} e / m_{e}}{\Omega_{\alpha, m} \Omega_{\beta, m} \Omega_{\gamma, m} \gamma_{0}^{6} v_{z 0}^{3}} \times\left(\frac{k_{\alpha, m}}{\Omega_{\alpha, m}}+\frac{k_{\beta, m}}{\Omega_{\beta, m}}+\frac{k_{\gamma, m}}{\Omega_{\gamma, m}}-\frac{3 v_{z 0}^{2} \gamma_{0}^{2}}{c^{2}}\right) ; \\
& C_{3, \beta, m}^{I I}=-k_{\beta, m} C_{3, \alpha, m}^{I I} / k_{\alpha, m} ; C_{3, \gamma, m}^{I I}=-k_{\gamma, m} C_{3, \alpha, m}^{I I} / k_{\alpha, m} \text {; } \\
& \omega_{p}^{2}=4 \pi n_{0} e^{2} / m_{e} . \\
& \Omega_{\chi, m}=m \omega_{\chi} / v_{z 0}-k_{\chi, m} \quad \gamma_{0}=1 / \sqrt{1-\left(v_{z 0} / c\right)^{2}} ;
\end{aligned}
$$

$v_{z 0}$ is the constant component of the REB velocity; $n_{0}$ is the electron concentration in the beam, $c$ is the speed of light in vacuum; $e=-|e|, m_{e}$ is the electron charge and mass, respectively.

Equation system (5) allows the investigation of multiharmonic processes in the FEL under study in quadratic nonlinear approximation.

\section{ANALYSIS}

Let us analyze the conditions of three-wave resonant interactions between longitudinal waves (2). It is easy to obtain the relations between frequencies and wave numbers for the slow and fast beam SCW from the dispersion relation (7):

$$
\begin{aligned}
& k_{\alpha, m}=m \omega_{\alpha} / v_{z 0}+\omega_{p} /\left(\gamma_{0}^{3 / 2} v_{z 0}\right), \\
& k_{\beta, m}=m \omega_{\beta} / v_{z 0}-\omega_{p} /\left(\gamma_{0}^{3 / 2} v_{z 0}\right)
\end{aligned}
$$

These relations verify that three-wave resonance conditions fulfillment between $m^{\text {th }}$ harmonics of slow, fast SCW and the first harmonic of the longitudinal pump wave follows the conditions (2) for slow and fast SCWs and longitudinal pump:

$$
\begin{gathered}
p_{\alpha, m}=p_{\beta, m}+p_{2,1} \text { or } m \omega_{\alpha}=m \omega_{\beta}, \\
k_{\alpha, m}=k_{\gamma, 1}+k_{\beta, 1} .
\end{gathered}
$$

In this case the wave number of the first harmonic of the electrostatic pump field takes the following value:

$$
k_{\gamma, 1}=2 \pi / \Lambda, \text { where } \Lambda=\pi \gamma_{0}^{3 / 2} v_{z 0} / \omega_{p}
$$

It follows from (10), (11) that the presence of a monochromatic electrostatic undulator is sufficient for the realization of many three-wave resonant interactions of longitudinal SCWs.

We consider a weak signal approximation assuming that the H-ubiton transverse and electrostatic longitudinal pump fields are sufficiently large and their changes can be neglected at the initial interaction stage. Higher harmonics of the interacting waves are not formed on this stage. Then using equations (5) we get the following statements for the first harmonics of the interacting waves:

$$
\begin{gathered}
C_{1,1,1} \frac{d E_{1,1}}{d z}=C_{3,1,1}^{I} E_{\alpha, 1} B_{2,1}^{*}, \\
C_{1, \alpha, 1} \frac{d E_{\alpha, 1}}{d z}=C_{3, \alpha, 1}^{I} E_{1,1} B_{2,1}+C_{3, \alpha, 1}^{I I} E_{\beta, 1} E_{\gamma, 1}, \\
C_{1, \beta, 1} \frac{d E_{\beta, 1}}{d z}=C_{3, \beta, 1}^{I I} E_{\alpha, 1} E_{\gamma, 1}^{*} .
\end{gathered}
$$

The solutions of the equation system (12) and the first equation of system (5) are expected to have the form $E_{1,1}, E_{\alpha, 1}, E_{\beta, 1} \sim \exp (\Gamma z)$. Substituting such solutions into these equations allows us finding an expression for the resulting wave growth rate in the studied FEL

$$
\Gamma=\sqrt{\Gamma_{\mathrm{I}}^{2}+\Gamma_{\mathrm{II}}^{2}}
$$

where

$$
\begin{gathered}
\Gamma_{\mathrm{I}}=\sqrt{\frac{C_{3,1,1}^{I}}{C_{1,1,1}} \cdot \frac{C_{3, \alpha, 1}^{I}}{C_{1, \alpha, 1}} \cdot\left|B_{2,1}\right|^{2}}, \\
\Gamma_{\mathrm{II}}=\sqrt{\frac{C_{3, \alpha, 1}^{I I}}{C_{1, \alpha, 1}} \cdot \frac{C_{3, \beta, 1}^{I I}}{C_{1, \beta, 1}} \cdot\left|E_{\gamma, 1}\right|^{2}}
\end{gathered}
$$

Note that the resulting growth rate $\Gamma$ is defined by both the parametric resonance of transverse waves growth rate $\Gamma_{\mathrm{I}} \sim\left|B_{2,1}\right|$ and the parametric resonance of longitudinal waves growth rate $\Gamma_{\text {II }} \sim\left|E_{\gamma, 1}\right|$.

We carry out numerical analysis of the growth rates depending on the system parameters. Fig. 2 shows the dependences of the growth rates on the relativistic factor of the electron beam. Curve 1 corresponds to the dependence $\Gamma_{\mathrm{I}}=\Gamma_{\mathrm{I}}\left(\gamma_{0}\right)$ determined by the parametric resonance of the transverse waves, curve $2-$ to the dependence $\Gamma_{\mathrm{II}}=\Gamma_{\mathrm{II}}\left(\gamma_{0}\right)$ determined by the parametric resonance of the longitudinal waves. Curve 3 represents the dependence of the resulting growth rate on the relativistic factor $\Gamma=\Gamma\left(\gamma_{0}\right)$. The curves are achieved under the condition that the first harmonic frequency of the electromagnetic signal is constant. The calculations are performed with the following system parameters: plasma beam frequency $\omega_{p}=3,0 \cdot 10^{10} \mathrm{~s}^{-1}$; the amplitude of the electric field strength of the longitudinal electrostatic pump field $E_{\gamma, 1}=30 \mathrm{kV} / \mathrm{cm}$, the magnetic field induction of the pump $B_{2,1}=0.02 \mathrm{~T}$; the 
cyclic frequency of the electromagnetic wave $\omega_{1,1}=3 \cdot 10^{12} \mathrm{~s}^{-1}$. It should be noted that such parameter values are quite moderate for the "ordinary" FELs $[10,12]$.

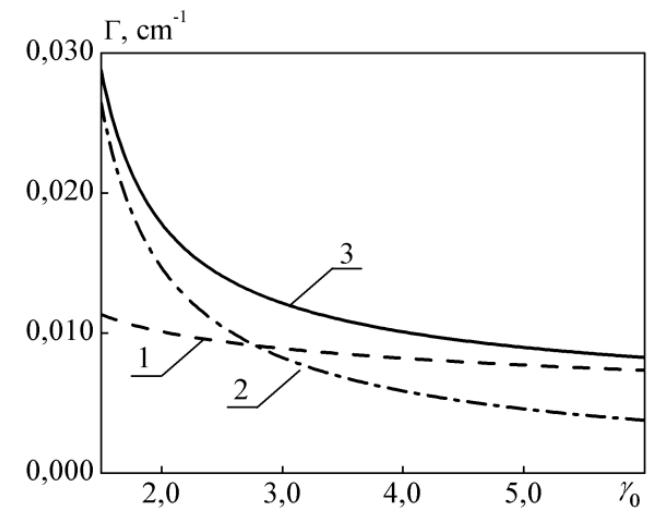

Fig. 2 - Wave growth rates dependences on beam relativistic factor. Curve 1 corresponds to the dependence $\Gamma_{\mathrm{I}}=\Gamma_{\mathrm{I}}\left(\gamma_{0}\right)$, curve 2 - to $\Gamma_{\mathrm{II}}=\Gamma_{\mathrm{II}}\left(\gamma_{0}\right)$, curve $3-$ to $\Gamma=\Gamma\left(\gamma_{0}\right)$

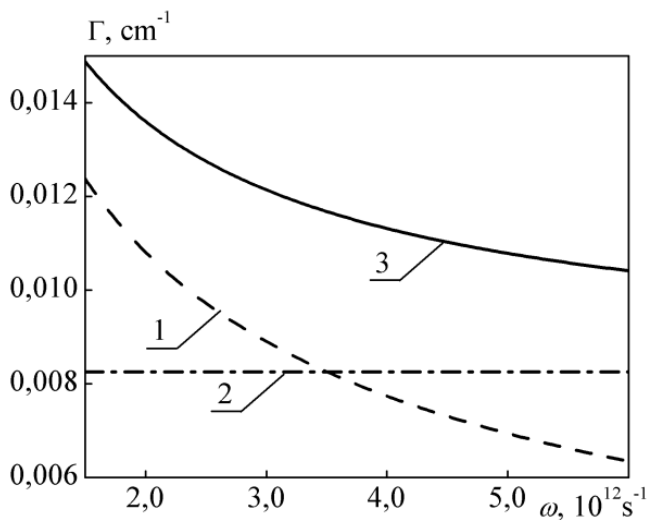

Fig. 2 - Wave growth rates dependences on electromagnetic signal frequency $\omega_{1}$. Curve 1 corresponds to the dependence $\Gamma_{\mathrm{I}}=\Gamma_{\mathrm{I}}\left(\omega_{1}\right)$, curve $2-$ to $\Gamma_{\mathrm{II}}=\Gamma_{\mathrm{II}}\left(\omega_{1}\right)$, curve $3-$ to $\Gamma=\Gamma\left(\omega_{1}\right)$

It follows from Fig. 2 that all growth rates decrease with the relativistic factor increasing. We also see that at low values of the relativistic factor $\gamma_{0}$ the growth rates $\Gamma_{\mathrm{II}}=\Gamma_{\mathrm{II}}\left(\gamma_{0}\right)$ (curve 2 ) determined by the parametric resonance of the longitudinal waves prevail over

\section{REFERENCES}

1. X. Zhang, Q. Xu, L. Xia, Y. Li, J. Gu, Z. Tian, C. Ouyang, J. Han, W. Zhang, Adv. Photon. 2 No 1, 014001 (2020).

2. G.-Q. Liao, Y.-T. Li, IEEE Trans. Plasma Sci. 47, 3002 (2019).

3. M. Perenzoni, D.J. Paul, Physics and Applications of Terahertz Radiation (Springer Netherlands: Dordrecht: 2014).

4. V.V. Kulish, A.V. Lysenko, I.V. Gubanov, A.Yu. Brusnik, Pat. 87750, Ukraine, MPK(2009): H05H 9/00, publ. 10.08.2009, bull. No 15/2009

5. G. Bekefi, R.E. Shefer, J. Appl. Phys. 50, 5158 (1979).

6. S.-C. Zhang, Phys. Plasma. 17, 053102 (2010). the rates $\Gamma_{\mathrm{I}}=\Gamma_{\mathrm{I}}\left(\gamma_{0}\right)$ (curve 1 ) determined by the parametric resonance of the transverse waves. Hence, the use of additional amplification by the longitudinal electrostatic undulator is the most effective at relatively low relativistic factors.

Fig. 3 shows the dependences of wave growth rates on the electromagnetic signal frequency $\omega_{1}$. Curve 1 corresponds to the dependence $\Gamma_{\mathrm{I}}=\Gamma_{\mathrm{I}}\left(\omega_{1}\right)$ determined by the parametric resonance of transverse waves. Curve 2 shows the dependence $\Gamma_{\mathrm{II}}=\Gamma_{\mathrm{II}}\left(\omega_{1}\right)$ determined by the parametric resonance of longitudinal waves. Curve 3 represents the dependence of the resulting growth increment on the signal frequency $\Gamma=\Gamma\left(\omega_{1}\right)$. The curves are obtained at a constant relativistic factor equal to three $\left(\gamma_{0}=3\right)$. The remaining system parameters are the same as for Fig. 2. It follows from Fig. 3 that the growth rate $\Gamma_{\mathrm{I}}=\Gamma_{\mathrm{I}}\left(\omega_{1}\right)$ determined by the parametric resonance of the transverse waves (curve 1) decreases with the frequency increasing, which correlates with previous studies $[10,12]$. The growth rate $\Gamma_{\mathrm{II}}=\Gamma_{\mathrm{II}}\left(\omega_{1}\right)$ associated with the wave amplification in longitudinal electrostatic undulator (curve 2) in the entire studied range remains almost constant. In this regard, the additional amplification of the waves created by the electrostatic undulator has a significant effect at high frequencies. Thus, the proposed FEL design works more efficiently at relatively high frequencies of the input electromagnetic signal.

\section{CONCLUSIONS}

Therefore, in the presented work within the framework of the quadratic approximation we elaborated the theory of superheterodyne FEL using the longitudinal electrostatic undulator for additional amplification of the electromagnetic signal wave. We discovered that the presence of the monochromatic electrostatic undulator was sufficient for the plurality of three-wave parametric resonant interactions of longitudinal SCWs to realize. We obtained and analyzed the expressions for the wave growth rate determined both by the parametric instabilities of the transverse and longitudinal waves in the electrostatic undulator. We demonstrated that the additional amplification provided by the electrostatic undulator was the most efficient for relatively small values of the beam relativistic factor and for sufficiently high values of the input electromagnetic signal frequency.

7. N. Sepehri Javan, Phys. Plasma. 19, 123106 (2012).

8. A.A. Kurayev, V.V. Matveyenko, A.K. Sinitsyn, Doklady BGUIR 6, 59 (2018).

9. V.V. Kulish, A.V. Lysenko, I.V. Gubanov, A.Yu. Brusnik, Probl. At. Sci. Technol. 3(91), 49 (2014).

10. V.V. Kulish, Hierarchic Electrodynamics and Free Electron Lasers: Concepts, Calculations, and Practical Applications (CRC Press: 2011).

11. V.V. Kulish, A.V. Lysenko, G.A. Oleksiienko, V.V. Koval, M.Y. Rombovsky, Acta Physica Polonica A 126, 1263 (2014).

12. H.P. Freund, Principles of Free Electron Lasers (Springer: 2018) 


\title{
До теорії супергетеродинних ЛВЕ з поздовжнім електростатичним ондулятором
}

\author{
О.В. Лисенко ${ }^{1}$, А.Ю. Брусник ${ }^{1}$ Ю.Ю. Волк ${ }^{1}$ М.О. Коровай ${ }^{1}$, С.С. Ільён ${ }^{1}$, О.Л. Бунецький ${ }^{2}$
}

${ }_{1}$ Сулський державний університет, вул. Рилського-Корсакова, 2, 40007 Сули, Украйна

${ }^{2}$ Інститут радіобізики та електроніки іл. О.Я. Усикова НАН України, вул. ак. Проскури, 12, 61085 Харків, Украӥна

\begin{abstract}
В рамках квадратичного нелінійного наближення проведено аналіз підсилювальних характеристик однопотокового супергетеродинного лазеру на вільних електронах, який використовує два механі зми підсилення електромагнітного сигналу: механізм параметричного підсилення електромагнітної хвилі з використанням традиційного ондулятора з поперечним періодично-реверсійним магнітним полем та додатковий механізм підсилення з використанням поздовжнього електростатичного ондулятора. За допомогою методу усереднених характеристик отримано систему диференціальних рівнянь, які описують динаміку амплітуд гармонік хвиль супергетеродинного лазеру на вільних електронах. З'ясовано, що в досліджуваній системі мають місце множинні трихвильові параметричні резонансні взаемодії між гармоніками хвиль просторового заряду різного типу. Для реалізації таких множинних взаемодій достатньо наявності монохроматичного електростатичного поля накачки. Отримано та проаналізовано вираз для інкременту зростання хвиль, який пов'язаний як параметричною нестійкістю поперечних хвиль, так і параметричною нестійкістю поздовжніх хвиль в електростатичному ондуляторі. Продемонстровано, що найбільш ефективно використовувати додаткове посилення, що забезпечуе електростатичний ондулятор, для систем, які характеризуються відносно невеликими значеннями релятивістського фактору пучка та доволі високими значеннями частоти електромагнітного сигналу. Продемонстрована перспективність використання таких супергетеродинних лазерів на вільних електронах з повздовжнім електростатичним ондулятором як потужних підсилювачів у міліметровомусубміліметровому діапазоні довжин хвиль.
\end{abstract}

Ключові слова: Супергетеродинний лазер на вільних електронах, Електростатичний ондулятор, Параметричний резонанс, Хвилі просторового заряду, Інкременти зростання хвиль. 